LA.UR. $95-1281$

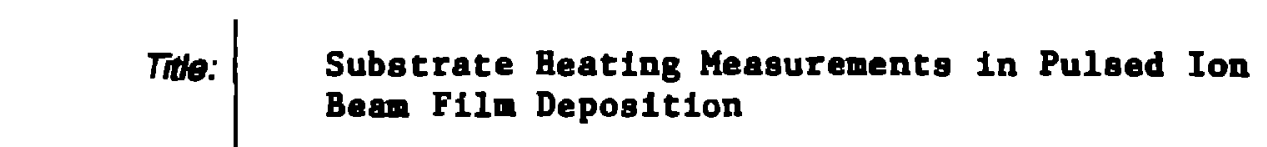

Submitted to:

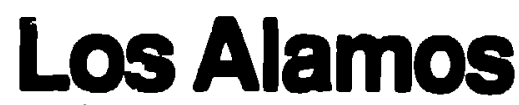

NATIONAL LABORATORY
J. C. 0180n
M. 0. Thomfson
H. A. Davis
D. J. Rej
W. J. Waganaar
D. R. Tallant

Apr11 17-21, 1995

San Francisco, California

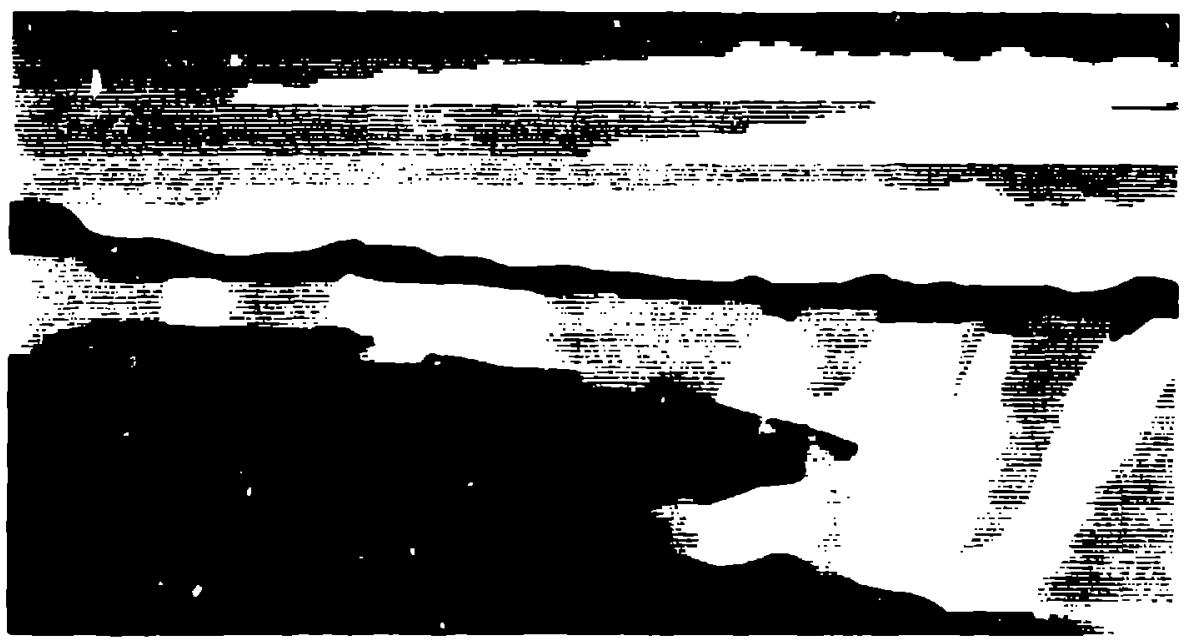

\section{RECEIVEO \\ MAY $O 8$ 195 \\ OSTI}

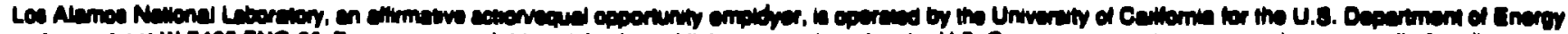

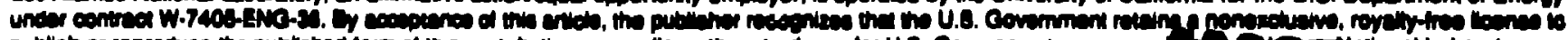

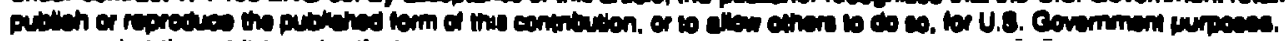




\title{
SUBSTRATE HEATING MEASUREMENTS IN PULSED ION BEAM FILM DEPOSITION
}

\author{
J. C. Olson", M. O. Thompson"*, H. A. Davis", D. J. Rej", W. J. Waganaar", and \\ D. R. Tallant \\ -Los Alamos National Laboratory, MS-E526, Los Alamos, NM 87544 \\ - Materials Science and Engineering Department, Cornell Univeraity, Ithaca, NY 14853 \\ -"Sandia National Laboratories, P. O. Box 5800, Albuquerque, NM 87185-0343
}

\begin{abstract}
Diamond-like Carbon(DLC) films have been depceited at Los Alamos National Laboratory by pulsed ion beam ablation of graphite targets. The targets were illuminated by an intense beam of hydrogen, carbon, and oxygen ions at a fluence of $15-45 \mathrm{~J} / \mathrm{cm}^{2}$. Ion energies were on the order of $350 \mathrm{keV}$, with beam current rising to $35 \mathrm{kA}$ over a $400 \mathrm{ng}$ ion current pulse.

Raman spectra of the deposited films indicate an increasing ratio of $s p^{3}$ to $s p^{2}$ bonding as the substrate is moved further away from the target and further off the target normal. Using a thin film platinum resistor at varying positions, we have measured the heating of the substrate ourface due to the kinetic energy and heat of condensation of the ablated material. This information is used to determine if substrate heating is responsible for the lack of DLC in positions close to the target and near the target normal. Latest data and analysis will be presented.
\end{abstract}

\section{INTRODUCTION}

Pulsed ion beam deposition has the porential to become a low cost, high throughput (a few $\$ / \mathrm{m}^{2}$ at $50 \mathrm{~m}^{2} / \mathrm{hr}$ for $1 \mu \mathrm{m}$ coatings) film production process for flat panel displays, photovoltaic cells, and other applications. In this process, which is similar to pulsed laser deposition, an intense beam of ions $(100-1000 \mathrm{keV}, 10-100 \mathrm{kA}, 0.1-1.0 \mu \mathrm{s})$ is directed toward a target, ablating some target material which condenses on a substrate as a thin film. An ongoing effort at Los Alamos National Laboratory is examining both science and technology issues related to pulsed ion beam deposition. The present work is concerned with heating of the substrate by the hot. dense ablation plume from a graphite target and the effect of this heating on the properties of the deposited material. Substrate heating by the ablated material was examined using thin film metal thermometers.

\section{EXPERIMENTAL SETUP}

A schematic of the experimental configuration is shown in Figure 1. The Anaconda generator at Los Alamos produced the intense ion beams used in these experiments. The machine is coupled to a focusing magnetically insulated diode, out of which a $400 \mathrm{keV}$, $30 \mathrm{kA}, 700 \mathrm{~ns}$ ion beam is extracted. Ablation targets are placed $35 \mathrm{~cm}$ from the anode, at the beam focus, where a peak beam energy density of approximatcly $30( \pm 15) \mathrm{J} / \mathrm{cm}^{2}$ is 


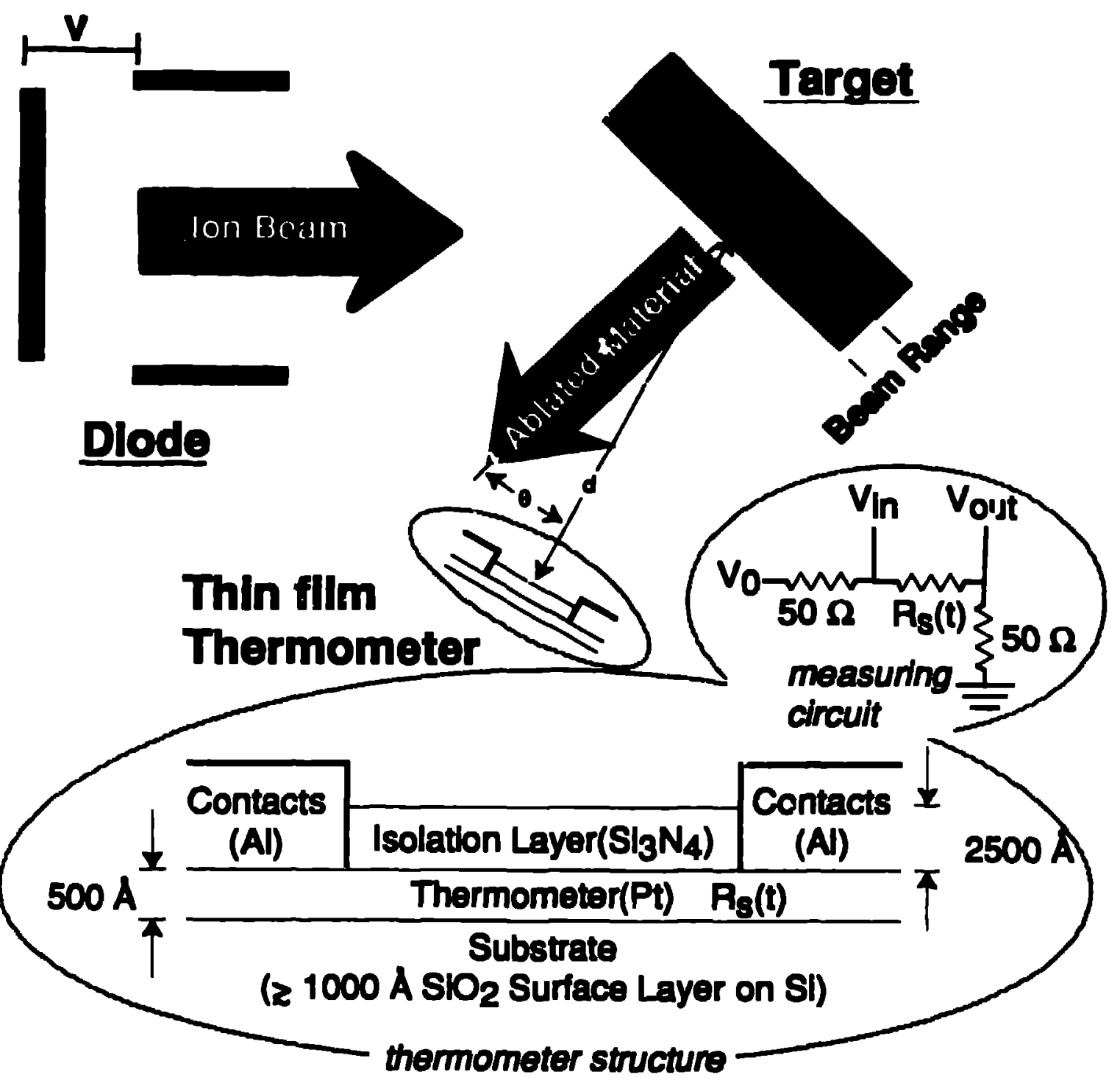

FIG. 1. Schematic of the experimental cetup and the thin film thermometer.

delivered $[1,2]$. A single machine pulse typically ablates $10 \mathrm{mg}$ of carbon from a POCO graphite target.

Substrate heating for various target-substrate separations and orientations was examined by the use of thin film metal thermometers. This technique, which relies on the temperature dependent resistance of a thin metal film to provide heating information with nanosecond time resolution, has previously been uned to examine ablntion in pulsed laser deposition experiments and melt dynamics in pulsed laser induced melting experiments [3-7]. Our experiments varied the target-thermometer separation, $d$, from 10 to $20 \mathrm{~cm}$ and varied the thermometer position relative to the target normal from $\theta=0$ to $0=30^{\circ}$.

Thermometer construction and a circuit description are shown in Figure 1. The relatively thick (2500 A) $\mathrm{Si}_{3} \mathrm{~N}_{4}$ isolation layer served two purposes: to diminish capacitive copling between the thermometer and beam created plames; and. more importantly; to prevent piessnas from shorting out the resistance of the thermometer. Details aboul the fabrication and calibration of this type of thermomete: may be found elsewhere [3]. Thermometers in our experiments had room temperature resistances around $150 \Omega$ and temperature roefficients of resistance $\left(\gamma=1 / R d R^{\prime} d \Gamma\right)$ of $0.0032 K^{-1}$. 
Tempurature measurement was accomplished by measuring the time-dependent thermometer resistance, $R_{d}(t)$. This was done by applying a pulsed bias, $V_{0}$, of $10 \mathrm{~V}$ to the measuring circuit. The voitages above and below (with respect to ground potential) the thin film thermometer layer, $V_{\text {in }}(t)$ an $t V_{\text {out }}(t)$, respectively, were monitored uing HP54111D digitizing oscilloscopes. $R_{s}(t)$ was then calculated from

$$
R_{0}(t)=\frac{100}{\frac{V_{0}}{V_{\text {in }}(t)-V_{\text {oet }}(t)}-1} .
$$

The quantity $V_{\text {in }}(t)-V_{\text {ous }}(t)$ should remain equal to $V_{0}$ and provided a measure of the noise. Using (1), the time dependent thermometer temperature was computed from

$$
T(t)=\frac{1}{\gamma} \frac{R_{s}(t)-R_{s}(0)}{R_{s}(0)}
$$

Heating power on the substrate was found by deconvolving the solution to the heat equation

$$
T(t)=\int_{0}^{t} \frac{P\left(t^{\prime}\right)}{\sqrt{\pi \rho c_{p} \kappa\left(t-t^{\prime}\right)}} d t^{\prime}
$$

where $\rho, c_{p}$ and $\kappa$ are the density, heat capacity, and thermal conductivity of the thermometer. For the time scales of interest in our experiment, it is sufficient to use $\rho, c_{p}$ and $\kappa$ for the bulk material, namely silicon. From the form of (3) it is ciear that the experimentally measured $T(t)$ can be applied to other substrate materials simply by scaling by the appropriate $\rho, c_{p}$ and $\kappa$.

\section{RESULTS}

Figure 2 shows the substrate temperature rise during carbon deposition at three different positions: $d=15 \mathrm{~cm}, \theta=0^{\circ} ; d=20 \mathrm{~cm}, \theta=0^{\circ} ;$ and $d=20 \mathrm{~cm}, \theta=30^{\circ}$. Figure 3 shows the heating power due to the ablation plume at the same three positions, and Figure 4 shows the estimated temperature rise of a glass substrate at those positions. We also took data with the conditions $d=10 \mathrm{~cm}, \theta=0^{\circ}$.

Expansion of the plume is clearly evident in the power data. Substratc heating decreased with increasing angle and with increasing target substrate separation, from $70 \mathrm{~kW} / \mathrm{cm}^{2}$ for approximately $10 \mu \mathrm{s}$ at $d=10 \mathrm{~cm}, \theta=0^{\circ}$ to $5 \mathrm{~kW} / \mathrm{cm}^{2}$ for approximately $20 \mu \mathrm{s}$ at $d=20 \mathrm{~cm}$, $\theta=30^{\circ}$. Arrival time of the leading edge of the ablation plume was used to compute a plume expansion velocity. The measured value was $1 \mathrm{~cm} / \mu \mathrm{s}$ on the target normal, decreasing to $0.4 \mathrm{~cm} / \mu \mathrm{s}$ at $\theta=30^{\circ}$. These values are necessarily crude, due to low statistics and large shot to shot irreproducibilities in the pulsed ion beam, but never the less are in reasonable agreement with the plume expansion velocity of $2 \mathrm{~cm} / \mu \mathrm{s}$ measured by visible light framing pictures. A better meesure of the plume energy content can be made by integrating the power to find energy, and dividing the energy by the number of atoms deposited. $25 \mathrm{~nm}$ of film at a density of $1.7( \pm 0.3) \mathrm{g} / \mathrm{cm}^{2}$ is deposited in a typical pulse [8], and the energy found by integrating the power curve for either position on the normal is $0.7 \mathrm{~J} / \mathrm{cm}^{2}$, giving a plume cnergy of $19 \mathrm{cV} /$ particle. This calculation assumes that all the heat absorbed by the substrate is contributed by particles which condense on the surface, and is therefore likely to be an overestimate of the plume temperalure. 


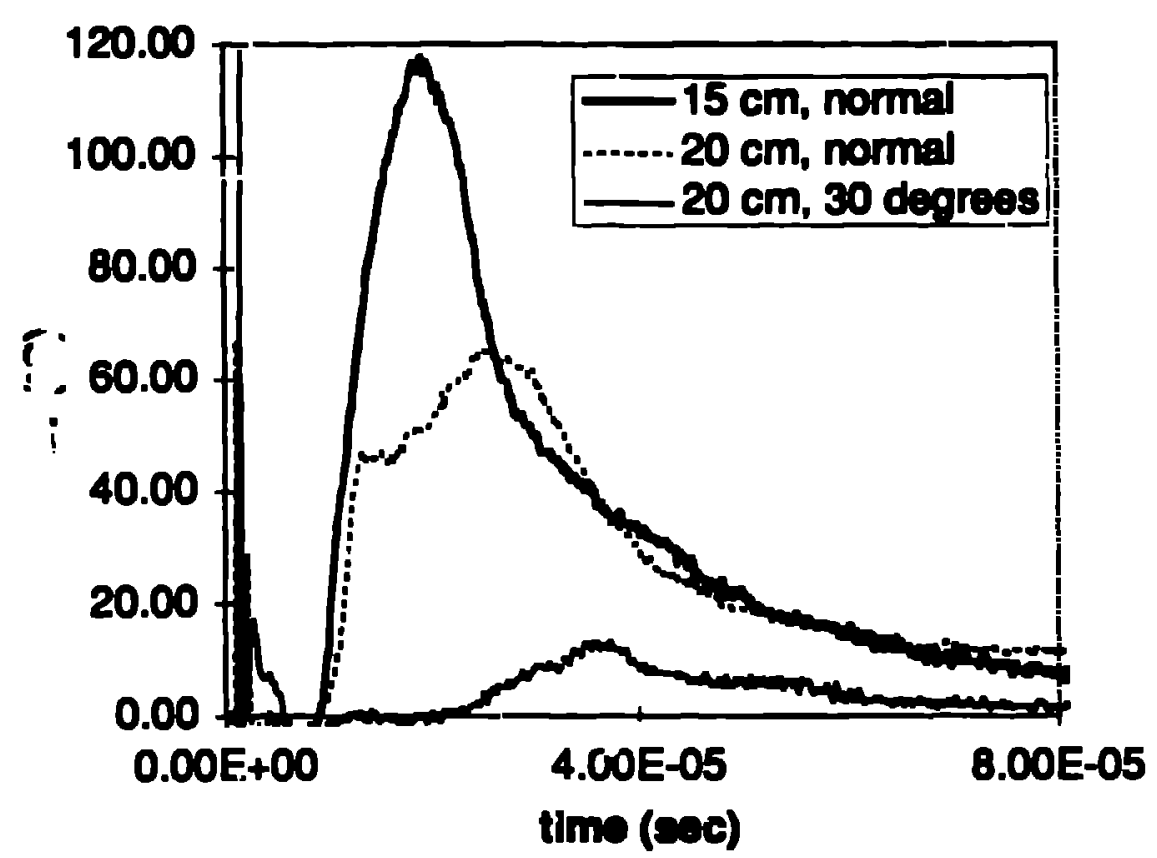

FIG. 2. Temperature rise as measured by thin film thermometers located: $d=15 \mathrm{~cm}, \theta=0^{\circ}$ (thick solid line); $d=20 \mathrm{~cm} . \theta=0^{\circ}$ (thin dashed line); and $d=20 \mathrm{~cm}, \theta=30^{\circ}$ (thin solid line).

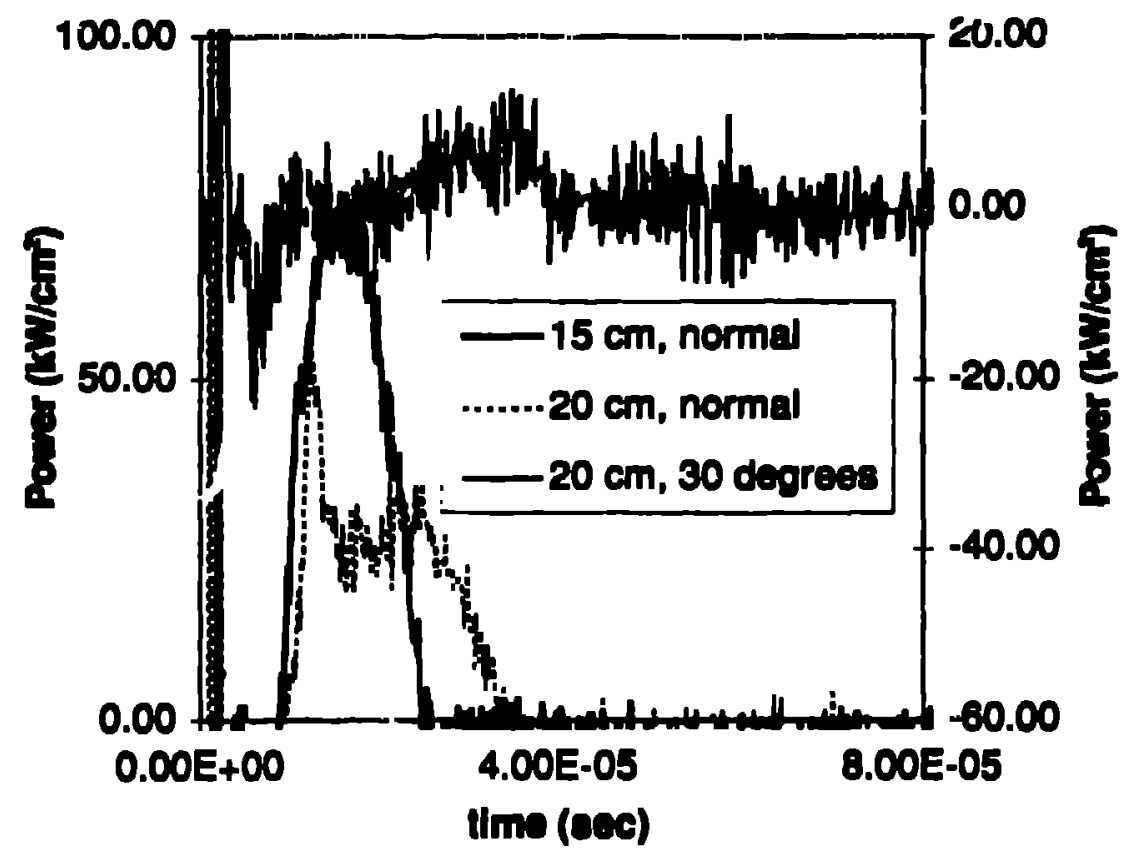

F1G. 3. Calculated heating power due to the ablation plume at positions: $d=15 \mathrm{~cm}, \theta=0^{\circ}$ (thick solid line - left vertical axio); $d=20 \mathrm{~cm}, \theta=0^{\circ}$ (thin dashed line - left vertical axis); and $l=20 \mathrm{~cm}, \theta=0^{\circ}$ (thin solid line - right vertical axis). 


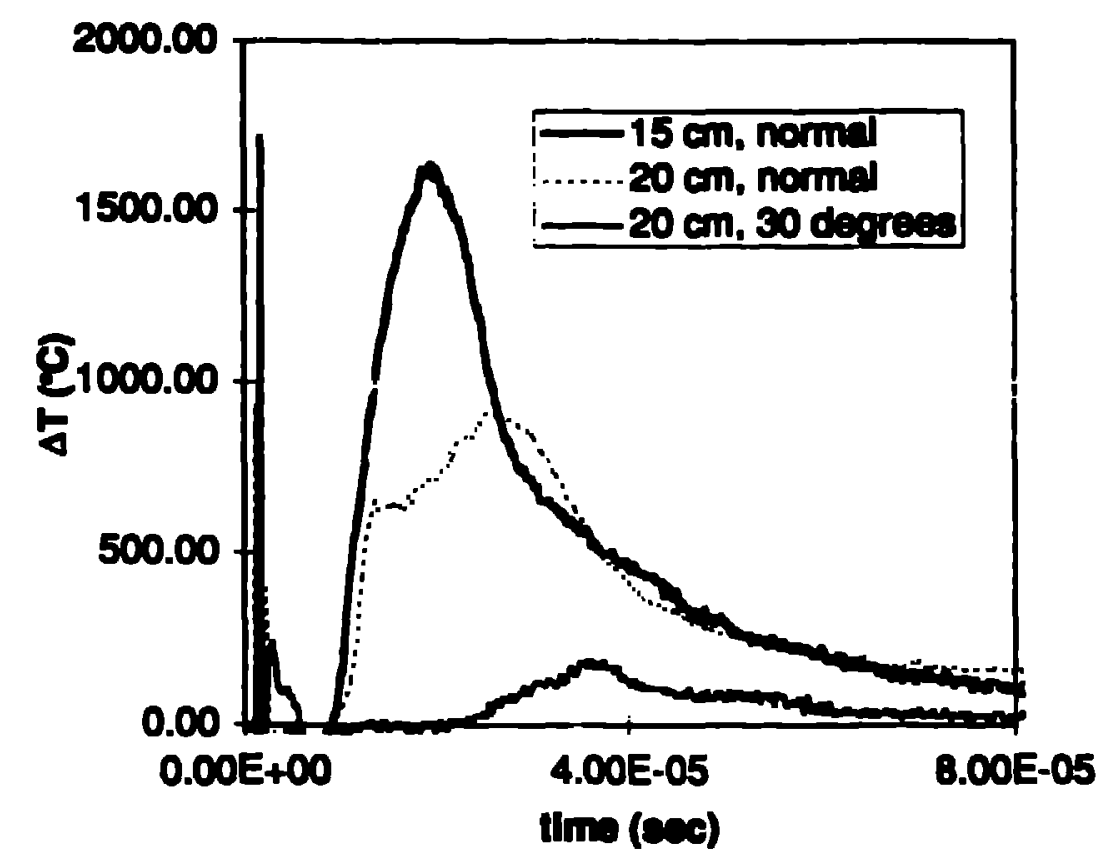

FIG. 4. Calculated ourface teriperature rive for glans subatrates lucated: $d=15 \mathrm{~cm}, \theta=0^{\circ}$ (thick solid line); $d=20 \mathrm{~cm}, \theta=0^{\circ}$ (thin dashed line); and $d=20 \mathrm{~cm}, \theta=30^{\circ}$ (thin solid line).

\section{DISCUSSION}

The Raman spect::a of films deposited at $d=22.5 \mathrm{~cm}, \theta=0^{\circ}$ and $d=15 \mathrm{~cm}, \theta=50^{\circ}$ showed diamond like character, but the film obtained at $d=15 \mathrm{~cm}, \theta=0^{\circ}$ was glasay [8]. This appears to be due to the high substrate temperature reached during depcoition at this position, which promotes formation of thermndynamically stable $s p^{2}$ bonds. Plume energies appear well-ouited to the formation of diamond-like carbon [9], and deposition onto a more thermally conductive substrate should allow the production of high quality DLC fims at high rates even on the target normal at low target-substrate separations.

\section{ACKNOWLPDGMENTS}

This work was supported by the U. S. Department of Energy, under cuntract number W-7405-ENG-36, through Los Alamos National Laboratory, Laborato:y Directed Research and Development. One of us (JCO) was supported by the Director's Office of Los Alamos National Laboratory through a Director's Funded Postdor toral Fellowship. 


\section{REFERENCES}

[1] H. A. Davis et al., in Proceedings of the Tenth International Conference on High-Power Particle Bisamo(NTIS PB95-144917), edited by W. Rix and R. White (National Technical Information Service, Springfield, VA, 1994).

[2] D. J. Rej et al., The Review of Scientific Inatruments 04, 2753 (1993).

[3] D. P. Brunco el al., The Revier of Scientific Instruments 64. 2615 (1993).

[4] J. A. Kittl et al., Journal of Applied Physics 78, 3725 (1993).

[5] D. P. Brunco, M. O. Thampson, C. E. Otis, and P. M. Goodwin, Journal of Applied Physica 72, 4344 (1992).

[6] J. Y. Tano, S. T. Picraux, P. S. Peercy, and M. O. Thompaon, Applied Physics Lettere 48, 278 (1986).

[7] M.. O. Thompeon et al., Applied Phyvics Lettere 42, 445 (1983).

[8] G. P. Johnaton et al., Journal of Applied Physics 78, 5949 (1994).

[9] J. J. Cuomo et al., Journal of Applied Physics 70, 1706 (1991).

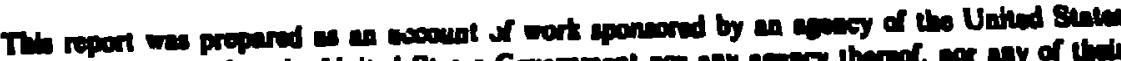

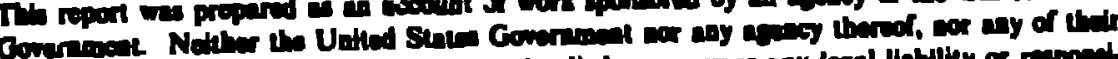

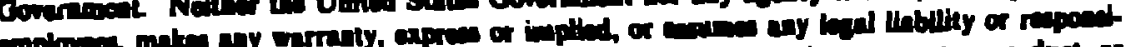

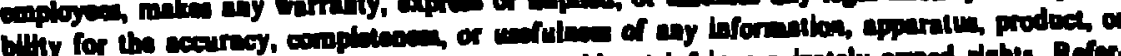

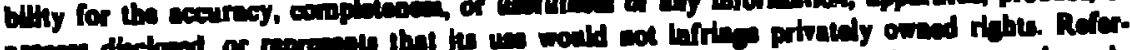

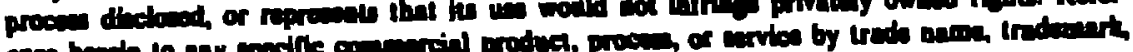

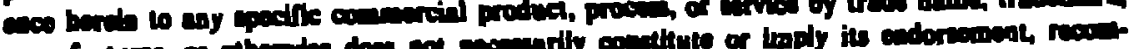

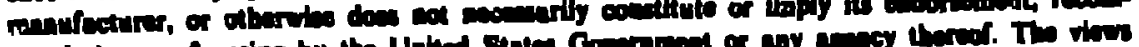

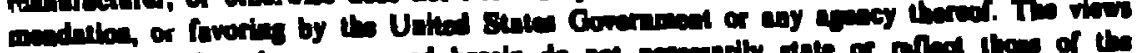

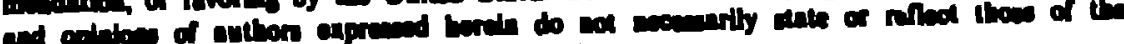

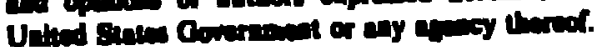

